metabolism) or the addition of borage oil (which contains $\gamma$-linolenic acid (18:3n-6), the $\Delta 6$ desaturation product) in the diet can facilitate the biosynthesis of $20: 4 n-6$ from linoleic acid $(18: 2 n-6)$, in vitro and ex vivo.

In a first set of experiments, male rats of the Zucker strain were divided into 4 groups of 6 animals: 2 groups of untreated, obese and lean, and 2 groups of treated animals. They received a daily dose of $2 \mathrm{mg} / \mathrm{kg}$ body weight of simvastatin in $0.1 \mathrm{ml}$ of corn oil by gastric intubation for $13 \mathrm{~d}$. All the animals were killed on day 14 . In the second set of experiments, rats were also divided into 4 groups of 6 animals each, 2 groups were maintained for 12 weeks on a diet (5\% w/w fat) containing borage oil $(18: 2+18: 3 n-6)$, whereas the other groups continued to receive the control diet ( $5 \% \mathrm{w} / \mathrm{w}$ fat) with $18: 2 n-6$ only. The food intake was adjusted to $20 \mathrm{~g} / \mathrm{d} / \mathrm{rat}$.

The animals were killed and the liver microsomes were isolated. The conditions of desaturase assay and fatty-acid analysis (GLC and HPLC) were essentially those previously described [Maniongui et al (1993) Lipids 28, 291297]. Saturating levels of ${ }^{14} \mathrm{C}$ substrates were used $\left(120 \mathrm{nmol}\right.$ of ${ }^{14} \mathrm{C} 18: 2 \mathrm{n}-6$ and $80 \mathrm{nmol}$ of $\left.{ }^{14} \mathrm{C} 20: 3 n-6\right)$.

Treatment with simvastatin did not change $\Delta 6$ desaturase specific activity (SA) in either phenotype, but increased $\Delta 5$ desaturase SA in obese rat $(+28 \%)$. The same effect had been observed with fenofibrate, another hypolipidemic drug [Blond et al (1989) Biochem Pharmacol 38, 27412744]. However, 18:3n-6 supplementation increased $(+39.7 \%) \Delta 6$ desaturase SA in the liver of the obese rats only. The changes in the rates measured in vitro were not accompanied by an increase in the level of 20:4n-6 in liver microsomal phospholipids. Our results suggest that the experimental conditions ( $2 \mathrm{mg}$ simvastatin for $13 \mathrm{~d}$ or $45 \mathrm{mg} / \mathrm{d} / \mathrm{rat} 18: 3 \mathrm{n}-6$ for 12 weeks) were beneficial by increasing both desaturase activities in vitro but were unable to restore a fatty-acid profile in obese rats close to that observed in lean rats. Because of the relatively low turnover of phospholipids, prolonged treatment with simvastatin or $18: 3 n-6$ supplementation may be beneficial by increasing the production of $n-6$ polyunsaturated fatty acids in vivo.

\section{Growth of muscle satellite cells isolated from chickens of 2 lines divergently}

selected for fast or slow growth. MJ Duclos, B Chevalier, FH Ricard, J Simon (INRA-Tours, Station de Recherches Avicoles, 37380 Nouzilly, France)

Fast and slow growing lines of chickens (FG and SG) have been divergently selected [Ricard (1975) Ann Genet Select Anim 7, 427-443]. At hatching, chicks of both lines weight about the same but as growth proceeds, $F G$ chickens are always heavier than SG at the same age. They also have significantly heavier muscles associated with larger muscle fibers [Rémignon et al (1994) Br Poult Sci 35, 65-76]. The fact that muscle fiber growth is paralleled by an increase in the number of nuclei, due to the fusion of multiplying muscle satellite cells with existing fibers, suggests that satellite cells from those selected lines may have different growth potential.

Satellite cells were preparated from pectoralis muscles of day-old male chicks and DNA synthesis was measured by ${ }^{3} \mathrm{H}$-thymidine $\left({ }^{3} \mathrm{H}-\mathrm{THY}\right)$ incorporation as described in Duclos et al [(1991) $J$ Endocrinol 128, 35-42]. The metabolism of satellite cell derived myolubes was studied. ${ }^{3} \mathrm{H}$ aminoisobutyric acid ( ${ }^{3} \mathrm{H}-\mathrm{AlB}$ ) or ${ }^{3} \mathrm{H}$-deoxy-D-glucose $\left({ }^{3} \mathrm{H}-\mathrm{DG}\right)$ uptake was measured following $4 \mathrm{~h}$ preincubation in DMEM $0.5 \%$ bovine serum albu$\min (D M E M / B S A)$ in the presence or absence of IGF-1. Protein synthesis was measured by ${ }^{3} \mathrm{H}$ tyrosine ( ${ }^{3} \mathrm{H}$-TYR) incorporation into proteins under similar conditions. For protein degradation studies, myotubes were incubated for $3 \mathrm{~d}$ in the presence of ${ }^{3} \mathrm{H}$-TYR to label proteins, and after washing, the release of ${ }^{3} \mathrm{H}-\mathrm{TY} \mathrm{R}$ was subsequently monitored over $24 \mathrm{~h}$. Data from 4-8 independent experiments, with a minimum of triplicate determinations per treatment within each experiment, were analysed by ANOVA and are presented as mean \pm standard error of the mean.

DNA synthesis was stimulated by fetal calf serum (FCS, $0.3-10 \%$ ) in a dose-dependent manner in satellite cells from both lines. The maximal stimulation was significantly higher $\left(F_{(1.240)}\right.$ $=197, P<0.01)$ in cells from FG chicks $(432 \pm$ $39 \%$ of basal with $2.5 \%$ FCS) than in cells from SG chicks $(317 \pm 22 \%)$. DNA synthesis was also stimulated by IGF-1 ( 10 or $100 \mathrm{ng} / \mathrm{ml}$ ) and a significantly larger stimulation was observed in $F G$ than SG cells $\left(F_{(1.72)}=20.5, P<0.01 ; 263 \pm 20 \%\right.$ of basal compared to $213 \pm 22 \%$ with $100 \mathrm{ng}$ IGF-1/ml, respectively).

None of the metabolic parameters differed between lines under basal conditions 
(DMEM/BSA). The amplitude of IGF-1 stimulated AIB uptake (about $300 \%$ of basal) and protein synthesis (about $130 \%$ of basal) did not differ between lines, whereas the IGF-1-stimulated DG uptake was higher in myotubes from the $F G$ line than from the $S G$ line $\left(F_{(1.69)}=4, P<0.01 ; 168 \pm\right.$ $12 \%$ vs $145 \pm 8 \%$ of basal, respectively). Following $24 \mathrm{~h}$ incubation of the myotubes in DMEM containing $0.5 \%$ Ultroser, protein degradation was similar in both lines (about $22 \%$ ).

Our data show that DNA synthesis by satelite cells from FG chicks is higher than that of cells from SG chicks in the presence of FCS or IGF-1. On the contrary, metabolic parameters of satellite cell derived myotubes and their response to IGF-1 were not affected by selection except for glucose uptake. Therefore, some growth-related pathways, but not all, have been modified by genetic selection for faster growth.

Proteolytic pathways involved in muscular dystrophy in mdx, dy/dy and mdf mice: a preliminary study. $L$ Combaret 1 , D Taillandier ${ }^{1}$, E Aurousseau ${ }^{1}, \mathrm{~L}$ Voisin ${ }^{1}$, D Meynial-Denis ${ }^{1}$, O Boespflug-Tanguy 2, JL Guénet ${ }^{3}$, D Attaix 1 ( ${ }^{1}$ INRA-Theix, Centre de Recherche en Nutrition Humaine et Unité d'Étude du Métabolisme Azoté, 63122 Saint-Genès-Champanelle; ${ }^{2}$ Laboratoire de Biochimie, Faculté de Médecine, 63001 Clermont-Ferrand Cedex; ${ }^{3}$ Unité de Génétique des Mammifères, Institut Pasteur, 75015 Paris, France)

Alterations in the structural, functional and metabolic properties of skeletal muscle or protein loss observed in muscular dystrophy may result from variations in protein synthesis and/or protein breakdown. The aim of the present study was to identify the proteolytic systems responsible for such alterations using Northern blot procedures, since mRNA levels proteases could be a sensitive index of increased protein breakdown [Attaix et al (1994) Reprod Nutr Dev 583-597] in $\mathrm{mdx}$ (lacking dystrophin and reproducing the Duchenne de Boulogne myopathy) in dy/dy (exhibiting muscle atrophy presumably due to neuronal defects) and mdf mice (characterized by a preferential loss of type I fibers).

Three groups of $\mathrm{mdx}, \mathrm{dy} / \mathrm{dy}$ and $\mathrm{mdf}$ dysotrophic mice $(n=3-6)$ were studied at 6,6 and 8 weeks of age respectively. $\mathrm{mdx}, \mathrm{dy} / \mathrm{dy}$ and mdt animals were compared to control Black 6 , OF1, and Black 6 mice, respectively, of the same age. Muscle atrophy was estimated by comparing the tibialis anterior muscle mass divided by the body weight, to compare dystrophic and control mice with slightly different live weights. The Northern blot procedures used to measure mRNA levels for cathepsin D, m-calpain, ubiquitin, and proteasome subunits were described by Taillandier [(1993) Thèse de Doctorat de l'Université BlaisePascal, Clermont-Ferrand II, France].

The $\mathrm{mdx}$ mice did not exhibit any muscle atrophy. Only the mRNA levels for m-calpain, but not for cathepsin D or ubiquitin, were higher in $\mathrm{mdx}$ mice than in controls, suggesting a selective activation of the $\mathrm{Ca}^{2+}$-dependent proteolytic pathway, in accordance with previous observations by Turner et al [(1988) Nature 335, 735-738]. By contrast, in dy/dy mice that present a small atrophy of the tibialis anterior muscle $(26 \%, P>0.05)$ only the expression of polyubiquitin was higher than in control mice, mRNA levels for cathepsin D, $\mathrm{m}$-calpain and the $\mathrm{C} 2$ proteasome subunit being systematically lower than in controls. These data suggest a possible inhibition of the different proteolytic pathways in dy/dy mice. Finally, the large atrophy of the tibialis anterior muscle observed in mdf mice $(71 \%, P<0.001)$ probably totally resulted from impaired protein synthesis, since no variation in mRNA levels for cathepsin $D, m-$ calpain, ubiquitin and C9 the proteasome subunit was observed in this model of dystrophy.

Taken together, these preliminary data clearly indicate that the activation of a given proteolytic system totally depends on the type of muscular dystrophy.

Effect of lipoprotein lipase polymorphisms on lipid levels in obese patients before and after a hypocaloric diet. R Jemaa, S Tuzet, F Fumeron, D Betoulle, M Apfelbaum (INSERM, U 286, Faculté XavierBichat, rue H-Huchard, 75018 Paris, France)

Obesity is frequently associated with hypertriglyceridemia and hypoHDLemia [Criqui et at (1986) Circulation 73 (suppl 1), 140-150]. A hypocaloric diet is accompanied by a decrease in lipid levels. Individual variations in the response to dietary modification are likely to be attributable to both environmental and genetic factors. The lipoprotein lipase (LPL) plays a key role in the 